Check for updates

Cite this: Chem. Sci., 2018, 9, 7874

๑ All publication charges for this article have been paid for by the Royal Society of Chemistry

Received 4th June 2018

Accepted 20th August 2018

DOI: $10.1039 / \mathrm{c} 8 \mathrm{sc} 02456 \mathrm{a}$

rsc.li/chemical-science

\section{Chemically stable ionic viologen-organic network: an efficient scavenger of toxic oxo-anions from water $\dagger$}

\author{
Partha Samanta, (D) a Priyanshu Chandra, $\ddagger^{a}$ Subhajit Dutta, (ID $\ddagger^{a}$ Aamod V. Desai (D) ${ }^{a}$ \\ and Sujit K. Ghosh (D) *ab
}

Detoxification of water has been demonstrated with a viologen-based cationic organic network (compound-1), which was stable not only in water, but also in acidic and basic media. The presence of free exchangeable $\mathrm{Cl}^{-}$ions inside the network of compound-1 and a high physiochemical stability of the materials offered a suitable scope for the capture of hazardous anionic pollutants from water. Rapid removal of the toxic water pollutant and carcinogenic chromate $\left(\mathrm{CrO}_{4}{ }^{2-}\right)$ from water was shown with compound-1. Furthermore, the oxo-anion of the radioactive isotope of technetium $\left({ }^{99} \mathrm{Tc}\right)$, i.e. the $\mathrm{TcO}_{4}{ }^{-}$ ion, also counts as a toxic water pollutant and by using surrogate anions $\left(\mathrm{MnO}_{4}{ }^{-}\right.$and $\left.\mathrm{ReO}_{4}{ }^{-}\right)$, a model capture study was performed. Notably, compound-1 showed high capacity values for each of the oxoanions and these were comparable to some of the well-performing compounds reported in the literature. Furthermore, to check the real time aspect, removal of all of the aforementioned anions from water was demonstrated, even in the presence of other concurrent anions.

\section{Introduction}

Increasing water pollution has become a global concern in recent years, and remediation of such toxic pollutants has drawn much attention worldwide. Pollution due to metal derived oxo-anions $\left(\mathrm{CrO}_{4}{ }^{2-}, \mathrm{TcO}_{4}{ }^{-}, \mathrm{SeO}_{3}{ }^{2-}, \mathrm{AsO}_{4}{ }^{3-}\right.$ etc. $)$ has become a pressing challenge, as most of them are omnipresent in the environment. ${ }^{1}$ Especially, $\mathrm{Cr}(\mathrm{vI})$ based oxo-anions are found to be very carcinogenic and mutagenic to living systems. ${ }^{2,3}$ Understanding the importance of this, the EPA (Environmental Protection Agency, U.S.) has included such oxoanions in the priority pollutant list. ${ }^{4,5}$ Chromate has been found in a wide range of applications in various industries like leather tanning, textile dyes and pigments, steel manufacturing, wood preservation, electroplating etc., where tanning industries alone discharge $\sim 30-35$ liters of $\mathrm{Cr}(\mathrm{vI})$ contaminated water for each kilogram of leather., ${ }^{6,7}$ It also affects the vitrification of low activity radioactive waste, as it forms spinels and has resulted in weakening the integrity of waste glass., ${ }^{8,9}$ Furthermore, the Hinkley groundwater contamination is one of the well known

\footnotetext{
${ }^{a}$ Department of Chemistry, Indian Institute of Science Education and Research, Dr. Homi Bhabha Road, Pashan, Pune 411008, India. E-mail: sghosh@iiserpune.ac.in; Tel: +912025908076

${ }^{b}$ Centre for Energy Science, IISER Pune, Dr. Homi Bhabha Road, Pashan, Pune 411008, India

† Electronic supplementary information (ESI) available. See DOI: 10.1039/c8sc02456a

\$ These authors contributed equally.
}

disasters caused by dumped $\mathrm{Cr}(\mathrm{VI})$ in California. ${ }^{\mathbf{1 0}}$ Apart from this case, several more incidents were found, and moreover the problems are still continuing, which has led researchers to design affordable and efficient techniques to capture $\mathrm{Cr}(\mathrm{vI})$ based oxo-anions. ${ }^{11,12}$ Apart from chromate, another oxo-anion, the pertechnetate $\left(\mathrm{TcO}_{4}{ }^{-}\right)$ion, has caused much concern as one isotope of technetium $\left({ }^{99} \mathrm{Tc}\right)$ is a radioactive element with a very high half-life time $\left(2.1 \times 10^{5}\right.$ years $) .{ }^{99}$ Tc has been found to be formed as a nuclear fission product of ${ }^{235} \mathrm{U}$ or ${ }^{239} \mathrm{Pu}$ with a high fission yield. Up to 2010 it was estimated that $\sim 305$ metric tons of ${ }^{99} \mathrm{Tc}$ was produced from weapons testing and nuclear reactors. ${ }^{13}$ Furthermore, Tc exists mostly as $\mathrm{TcO}_{4}{ }^{-}$in the environment, which is highly soluble in water with high mobility. As a consequence of this, $\mathrm{TcO}_{4}{ }^{-}$may also exist in low level waste. To date, many different techniques have been employed for the removal of oxo-anions, like ion exchange, chemical precipitation, adsorption, electrodialysis, photocatalysis etc. ${ }^{\mathbf{1 4 - 1 7}}$ The ion exchange method has been considered as a more efficient technique over the others owing to its low cost, being comparatively simple and safe, and its efficient performance even for waste which has a low concentration of pollutants etc. ${ }^{\mathbf{1 8 , 1 9}}$ Although several anion exchange resins have been reported, their poor selectivity, poor exchange kinetics and lack of stability have led researchers to render new materials for efficient oxo-anion capture from water. ${ }^{20}$ As an alternative, porous cationic framework based materials, such as layered double hydroxides (LDHs), metal-organic frameworks (MOFs) etc., have emerged in recent years. ${ }^{21-35}$ Recent reports have shown 
that both MOF and LDH materials can be useful for the removal of toxic and hazardous anionic pollutants from waste water. ${ }^{36-39}$

Progress in the area of porous materials has skyrocketed over the past few decades due to their wide range of applications. Among them, metal-organic frameworks (MOFs) and lately evolved porous organic materials have seen much progress in recent years over congener materials, because of features like amenability in their design, high surface areas and tuneable pore surfaces as per requirements. ${ }^{\mathbf{4 0 - 4 7}}$ Although MOFs have been employed to capture oxo-anions from water, a lack of sufficient physiochemical stability of most of the MOFs and difficulties in the bulk scale synthesis have hindered their applications. ${ }^{48,49}$ In contrast, porous organic materials are constructed from strong covalent bonds, which result in a high physiochemical stability. Such stability has made them one of the frontrunners in the area of porous materials, and it has been witnessed that for real time applications the stability has gained more priority over direct structure property correlations. ${ }^{50,51}$ These compounds have already acquired much attention in the field of gas adsorption, catalysis, drug delivery, fuel cell applications etc.; but are very rarely employed to capture hazardous oxo-anions from water. ${ }^{52-63}$ To execute anion capture via ion exchange, a cationic network with exchangeable anions is a primary requirement. But direct synthesis of such cationic organic frameworks has rarely been explored. ${ }^{64-68}$ In the literature very few reports are present on the direct synthesis of ionic organic frameworks, and viologen based organic frameworks are one of them, which have been synthesized via a Schiff base reaction, Sonogashira-Hagihara coupling, a Menshutkin reaction and trimerisation of -CN groups. ${ }^{69-73}$ Zincke's reaction is an effective tool to synthesize viologen based compounds in a single step, but this reaction has not been used much to synthesize extended porous organic networks. ${ }^{74-76}$ Trabolsi \& coworkers showed that the morphologies of compounds can be different depending on the polarity of solvents used during the synthesis, which can directly influence the properties of those compounds. ${ }^{74}$ Owing to such a structural diversity and chemical stability, cationic frameworks can be well suited to the capture of hazardous anionic pollutants from water. Herein, we have demonstrated the efficient capture of toxic oxo-anions with a viologen based organic network (compound-1) owing to its chemical stability and free exchangeable anions (Fig. 1).

\section{Experimental}

\section{Materials}

4,4'-Dipyridyl, 1-chloro-2,4-dinitrobenzene and 4-aminobenzonitrile were purchased from Sigma-Aldrich, $\mathrm{KReO}_{4}$ was purchased from Alfa-Aesar; triflic acid, $\mathrm{KMnO}_{4}$ and $\mathrm{K}_{2} \mathrm{CrO}_{4}$ and all other solvents were purchased locally. The obtained chemicals were used without any further purification.

\section{Physical measurements}

All infra-red (IR) spectra were recorded using a NICOLET 6700 FT-IR spectrophotometer, using $\mathrm{KBr}$ pellets in the range of 400$4000 \mathrm{~cm}^{-1}$. Thermogravimetric analysis (TGA) was recorded on

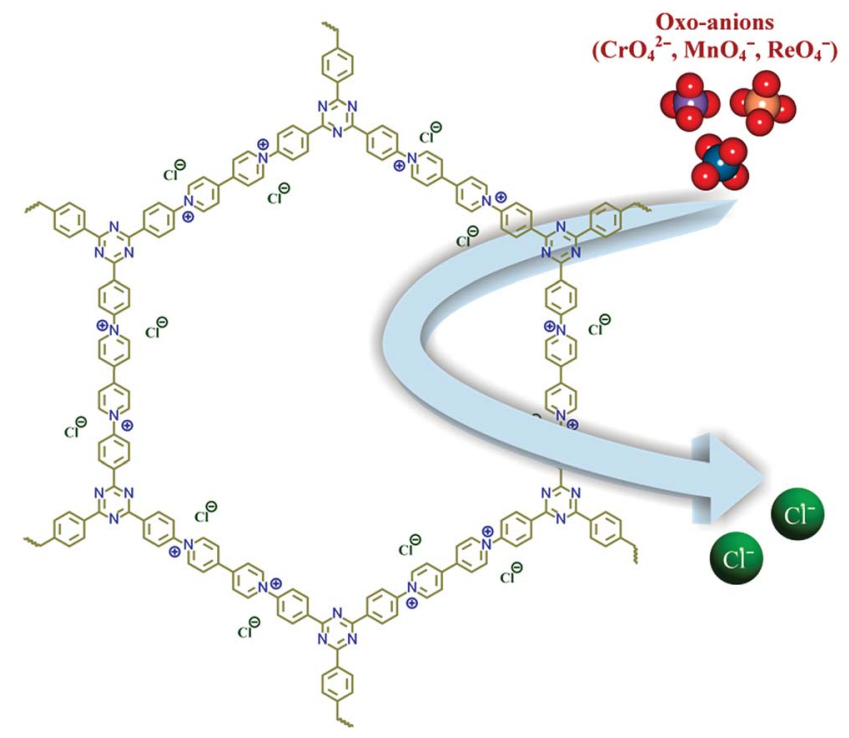

Fig. 1 Schematic representation of the oxo-anion capture in compound-1.

a Perkin-Elmer STA 6000 TGA analyser under an $\mathrm{N}_{2}$ atmosphere with a heating rate of $10{ }^{\circ} \mathrm{C} \mathrm{min}^{-1}$. Gas adsorption measurements were carried out using a BelSorp-max instrument from Bel Japan. FESEM was performed using a FEI Quanta 3D dual beam ESEM at $30 \mathrm{kV}$. UV spectra were acquired on a Shimadzu UV 2600 Spectrophotometer.

\section{Synthesis of $4,4^{\prime}, 4^{\prime \prime}$-(1,3,5-triazine-2,4,6-triyl)trianiline (precursor 1)}

Precursor 1 was synthesised from 4-aminobenzonitrile via an acid catalyzed trimerisation reaction by following a previously reported protocol. ${ }^{77}$

\section{Synthesis of 1,1'-bis(2,4-dinitrophenyl)-4,4'-bipyridinium dichloride (precursor 2)}

Precursor 2 was also synthesised by following a previously reported protocol. ${ }^{78}$

\section{Synthesis of compound-1}

Compound-1 was synthesized via the Zincke reaction of precursor 1 and 2 (Scheme S1†). First, a Schlenk tube was charged with $560 \mathrm{mg}$ of precursor $2(1 \mathrm{mmol})$ and $177 \mathrm{mg}$ of precursor 1 ( $0.5 \mathrm{mmol})$; then $20 \mathrm{~mL}$ of ethanol (EtOH), $20 \mathrm{~mL}$ of 1,4-dioxane and $20 \mathrm{~mL}$ of Cl-benzene were added respectively to the reaction mixture. After that, the reaction mixture was purged with $\mathrm{N}_{2}$ gas and allowed to reflux for 2 days under these conditions. After completion of the reaction, the reaction mixture was filtered and washed with different solvents like dimethylformamide (DMF), water, tetrahydrofuran (THF), MeCN, acetone, methanol (MeOH) and dichloromethane (DCM) to remove unreacted materials and small polymers (oligomers). A brown colored solid material was obtained, which was further kept in a $1: 1$ mixture of chloroform and THF to exchange guest 
a)

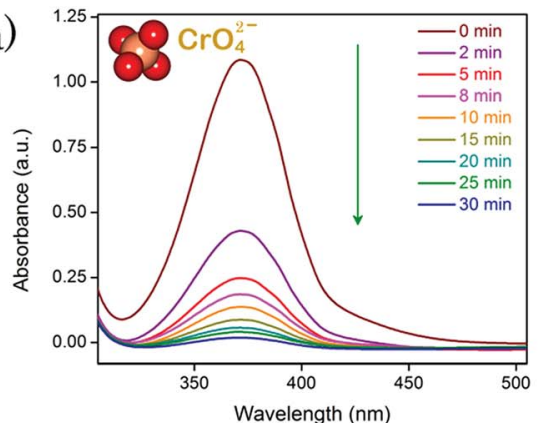

d)

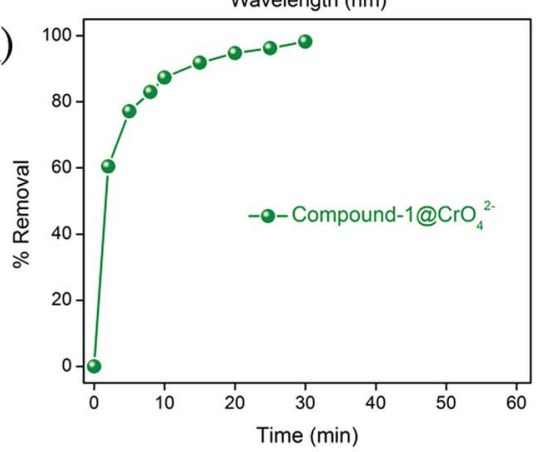

g)

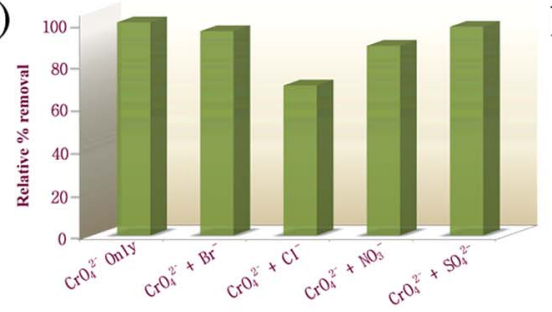

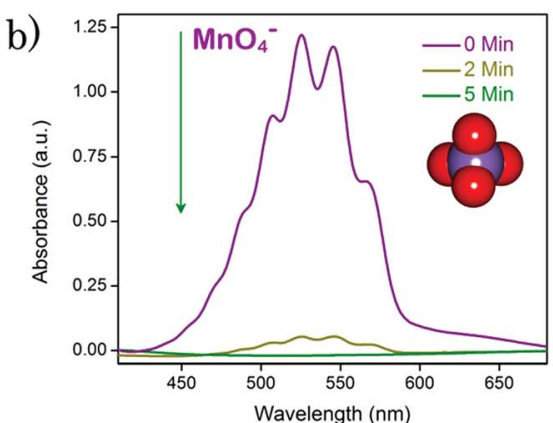

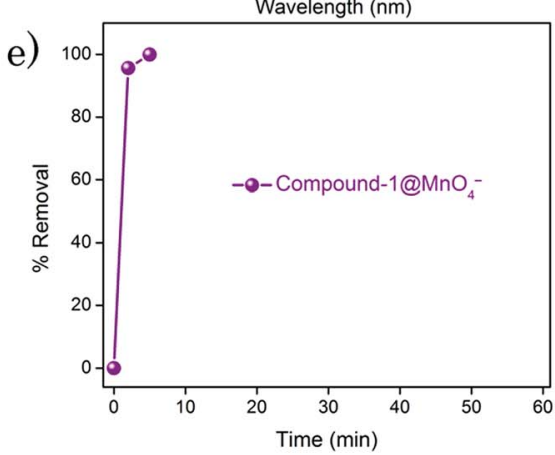

h)

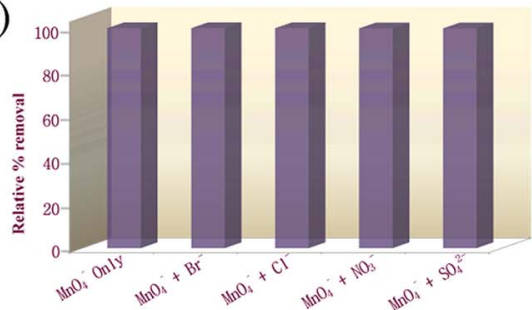

c)
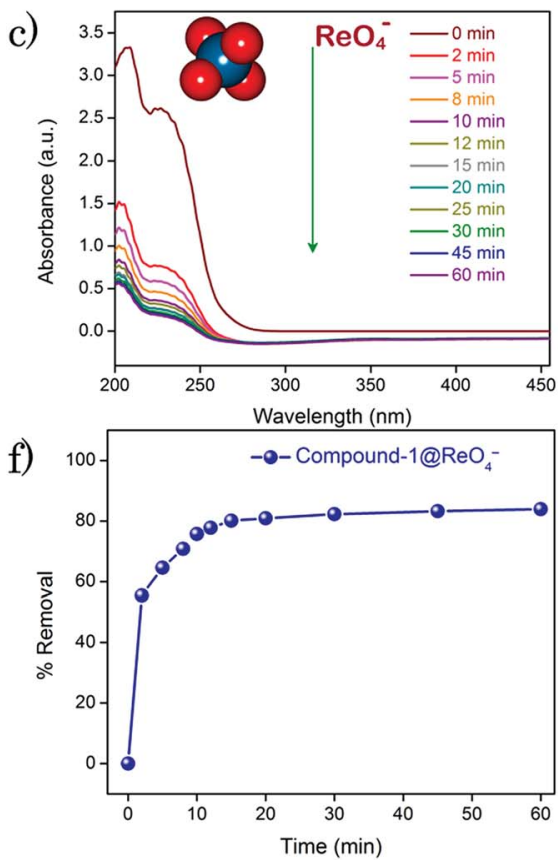

i)

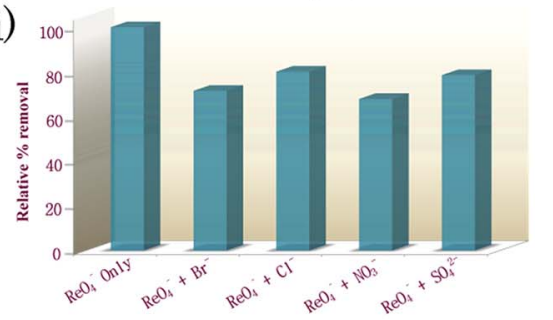

Fig. 2 UV-Vis spectroscopy in the presence of compound- 1 at different time intervals for the water solution of (a) $\mathrm{CrO}_{4}{ }^{2-}$ ions, (b) $\mathrm{MnO}_{4}{ }^{-}$ions and (c) $\mathrm{ReO}_{4}{ }^{-}$ions; removal (in \%) of (d) $\mathrm{CrO}_{4}{ }^{2-}$ ions, (e) $\mathrm{MnO}_{4}{ }^{-}$ions and (f) $\mathrm{ReO}_{4}{ }^{-}$ions with compound- 1 at different time intervals; the bar diagrams represent the removal efficiency of compound -1 in the presence of anions like $\mathrm{Cl}^{-}, \mathrm{Br}^{-}, \mathrm{NO}_{3}{ }^{-}$and $\mathrm{SO}_{4}{ }^{2-}$ for $(\mathrm{g}) \mathrm{CrO}_{4}{ }^{2-}$ ions, (h) $\mathrm{MnO}_{4}{ }^{-}$ ions and (i) $\mathrm{ReO}_{4}^{-}$ions.

molecules (with a high boiling point) with low boiling solvent molecules. After 4 days, the compound was filtered off and heated at $\sim 100{ }^{\circ} \mathrm{C}$ under vacuum to remove the occluded guest molecules. Yield: $240 \mathrm{mg}$.

\section{Time dependent study of oxo-anion removal}

In the case of the $\mathrm{CrO}_{4}{ }^{2-}$ removal study, we took $2 \mathrm{~mL}$ of an aqueous solution of $0.25 \mathrm{mM} \mathrm{CrO}_{4}{ }^{2-}$ ions in a cuvette and recorded the initial absorbance with UV-Vis spectroscopy. To the cuvette, $1 \mathrm{mg}$ of desolvated compound-1 was added, and after several time intervals we recorded the corresponding absorbance spectra of the supernatant solution. In a similar way, we carried out UV-Vis spectroscopy of $\mathrm{MnO}_{4}{ }^{-}$and $\mathrm{ReO}_{4}{ }^{-}$ ions. But in this case, we took an aqueous solution of $0.5 \mathrm{mM}$ for each of the $\mathrm{MnO}_{4}{ }^{-}$and $\mathrm{ReO}_{4}{ }^{-}$ions. Furthermore, from this time dependent study we calculated the \% removal and decrease in the concentration of the oxo-anions $v s$. time using the following equation, ${ }^{61}$

$$
D_{t}=\frac{C_{0}-C_{t}}{C_{0}} \times 100 \%=\frac{A_{0}-A_{t}}{A_{0}} \times 100 \%
$$

$$
\text { i.e., } \quad C_{t}=C_{0}-\frac{A_{0}-A_{t}}{A_{0}} \times C_{0}
$$

where $D_{t}$ is the exchange capacity, $C_{0}$ and $A_{0}$ are the initial concentration and absorbance of the oxo-anion solution respectively, and $C_{t}$ and $A_{t}$, are the concentration and absorbance of the oxo-anion solution at specific times respectively.

Furthermore, kinetics data for $\mathrm{CrO}_{4}{ }^{2-}$ and $\mathrm{ReO}_{4}{ }^{-}$ions were fitted in a pseudo second-order model with the help of the following equation, ${ }^{29}$

$$
Q_{t}=\frac{k_{2} Q_{\mathrm{e}}{ }^{2} t}{1+k_{2} Q_{\mathrm{e}} t}
$$

where, $t$ is the time in minutes, and $Q_{t}$ and $Q_{\mathrm{e}}$ are the amounts of adsorbate $\left(\mathrm{mg} \mathrm{g}^{-1}\right)$ on the adsorbent at different time intervals and at equilibrium respectively.

\section{Study of oxo-anion trapping in the presence of competing anions}

In this study, we took $\mathrm{Cl}^{-}, \mathrm{Br}^{-}, \mathrm{NO}_{3}{ }^{-}$and $\mathrm{SO}_{4}{ }^{2-}$ ions as the competing anions, which are omnipresent in common water sources and waste waters. We took an equimolar $(2.5 \mathrm{mM} ; 1: 1)$ 

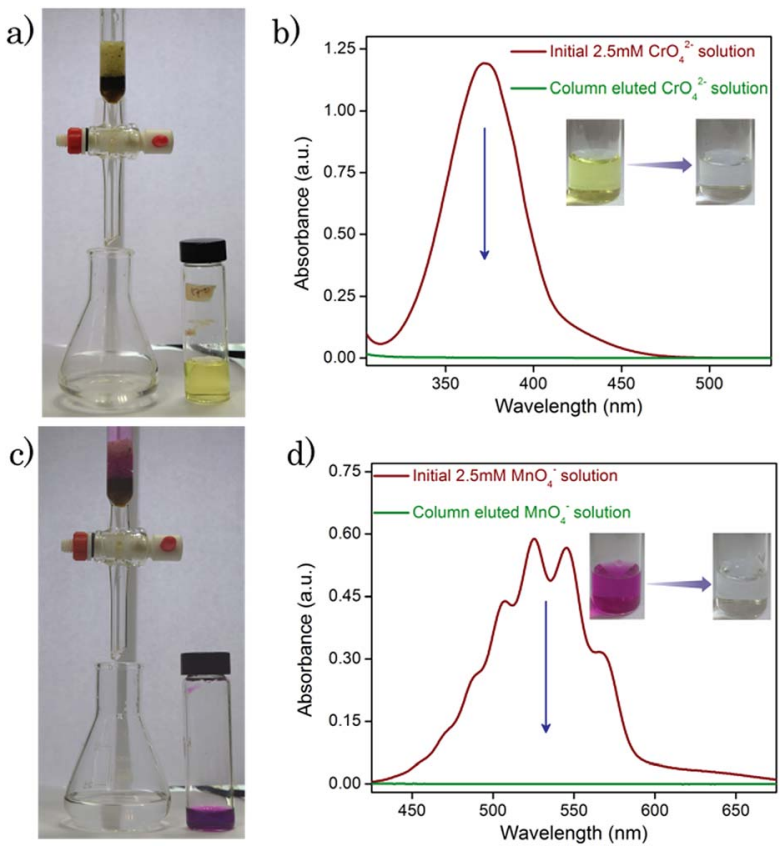

Fig. 3 (a) Image and (b) UV-Vis spectra of the $2.5 \mathrm{mM} \mathrm{CrO}_{4}{ }^{2-}$ solution before and after passing through the compound-1 loaded packed column; (c) image and (d) UV-Vis spectra of the $2.5 \mathrm{mM} \mathrm{MnO}_{4}{ }^{-}$ion solution before and after passing through the compound-1 loaded packed column.

aqueous solution of targeted oxo-anions and the competing anion. To the mixture, $2 \mathrm{mg}$ of desolvated compound-1 was added and stirred for 18 hours. After 18 hours, the solution was filtered off to separate compound-1, and the solution was characterised with UV-Vis spectroscopy. The obtained solution was diluted 10 times to measure the UV-Vis spectroscopy, and furthermore the capture efficiency of compound-1 in the presence of other anions was studied by comparison with a blank (Blank: only $2.5 \mathrm{mM}$ of the oxo-anion was taken instead of a mixture). Along with UV-Vis spectroscopy, this study was also affirmed by ICP-AES analyses.

\section{Calculation of capacity}

$5 \mathrm{mg}$ of desolvated compound-1 was kept with $2.5 \mathrm{~mL}$ of the $5 \mathrm{mM}$ oxo-anion solution for 24 hours under stirring conditions. After 1 day, compound-1 was filtered out and the filtrate was used for further characterisation. UV-Vis measurements were carried out by diluting the solution. From the initial and final absorbance values of the oxo-anion solutions we calculated the storage capacity of compound- $\mathbf{1}$ in 1 day using the following equation, ${ }^{61}$

$$
Q_{t}=\frac{\left(C_{0}-C_{t}\right) \times V}{m}
$$

where, $Q_{t}, C_{0}, C_{t}, V$ and $m$ are the capacity of the adsorbent, the initial concentration of the oxo-anion solution, the concentration of the oxo-anion solution at specific times, the volume of the solution and the mass used for the adsorbent respectively. Furthermore, the capacity for compound-1 was rechecked with ICP-AES analyses.

\section{Recyclability test of compound-1}

Compound-1 $\supset$ oxo-anion $(10 \mathrm{mg})$ was regenerated with a $3 \mathrm{M}$ $\mathrm{HCl}$ solution $(2 \mathrm{~mL})$ by keeping it for $\sim 20$ hours. ${ }^{35}$ Reusability of the regenerated material was checked with $5 \mathrm{~mL}$ of the $1 \mathrm{mM}$ oxo-anion $\left(\mathrm{CrO}_{4}{ }^{2-}\right.$ and $\left.\mathrm{ReO}_{4}{ }^{-}\right)$solutions. After $\sim 20$ hours, the concentrations of the oxo-anion solutions were measured by UV-Vis spectroscopy. These studies were repeated for up to four cycles for each of the cases $\left(\mathrm{CrO}_{4}{ }^{2-}\right.$ and $\mathrm{ReO}_{4}{ }^{-}$ions). Furthermore, a similar method was employed for the column where $3 \mathrm{M} \mathrm{HCl}$ was passed through the column to regenerate the material. Then, the $\mathrm{CrO}_{4}{ }^{2-}$ ion solution was passed through the column to check the performance.

\section{Results and discussion}

Compound-1 was synthesized from precursor 1 and 2 via Zincke's reaction and was found to be insoluble in various solvents, which indicated the formation of an extended network (Scheme S1 $\dagger$ ). Coskun \& co-workers recently reported the structure of compound-1, synthesized via the trimerisation of -CN groups in an ionothermal method. ${ }^{70}$ Very recently, Wen \& co-workers reported the compound via Zincke's reaction with the same precursors, but different reaction conditions resulted in a different morphology of the material and this was further employed for the electrosynthesis of $\mathrm{H}_{2} \mathrm{O}_{2}{ }^{76}$ Furthermore, to remove occluded solvent molecules, compound-1 was kept in $\mathrm{CHCl}_{3}$-THF (1:1) for 4 days and then desolvated under vacuum at $\sim 100{ }^{\circ} \mathrm{C}$. The desolvated phase was characterized with Fourier transform infra-red (FT-IR) spectroscopy, thermogravimetric analysis (TGA), solid state ${ }^{13} \mathrm{C}-\mathrm{NMR}$, gas adsorption, field emission scanning electron microscopy (FE-SEM) and EDX analysis. An almost negligible change in weight up to $\sim 250{ }^{\circ} \mathrm{C}$ in the TGA profile revealed the desolvation of compound-1 (Fig. S1 $\dagger$ ). Replacement of the 2,4-dinitroaniline via Zincke's reaction from precursor-2 was confirmed by FT-IR, as the peak at $\sim 1550 \mathrm{~cm}^{-1}$ (for $-\mathrm{NO}_{2}$ groups) disappeared in compound-1 (Fig. S2 $\dagger$ ). The amount of $\mathrm{N}_{2}$ uptake (at $77 \mathrm{~K}$ ) was found to be $34.2 \mathrm{~mL} \mathrm{~g}^{-1}$, and such a low uptake corroborated the presence of $\mathrm{Cl}^{-}$ions in compound-1 (Fig. S3 $\dagger$ ). Furthermore, $\mathrm{CO}_{2}$ adsorption at $195 \mathrm{~K}$ showed strong hysteresis in the desorption profile due to interactions between the $\mathrm{Cl}^{-}$ions and the $\mathrm{CO}_{2}$ molecules (Fig. $\mathrm{S} 4 \dagger$ ). A solid state ${ }^{13} \mathrm{C}$-NMR study supported the presence of the triazine core along with the viologen moiety in compound-1 (Fig. S5†). The presence of $\mathrm{Cl}^{-}$ions was verified by EDX analysis (Fig. S6-S8†). Furthermore, to check the chemical stability, we kept compound-1 $(25 \mathrm{mg})$ in $2 \mathrm{M} \mathrm{HCl}$ and $2 \mathrm{M} \mathrm{KOH}$ solutions for 7 days. After 1 week we found a negligible change in the weight for each, and further characterized these with FT-IR, TGA, FE-SEM and EDX analyses. No change in the FT-IR peak positions affirmed there were no changes in the functional groups (Fig. S9†). The morphologies of acid-base treated phases of compound-1 were also found to be unaltered in an FE-SEM study (Fig. S10†). The decomposition temperatures for each of the compounds were also found in a similar position to that of compound-1, which indicated that the networks remained similar (Fig. S13†). 
Enthused by such physiochemical stability and the presence of free $\mathrm{Cl}^{-}$ions inside compound-1, we sought to check an anion exchange study in a water medium. Due to the ionic nature of compound-1, it was well dispersed in water which can be advantageous for anion exchange studies. Furthermore, the yellow color of the $\mathrm{CrO}_{4}{ }^{2-}$ solution turned to colorless with time when compound-1 was added to it. Encouraged by this observation, we thought to perform the $\mathrm{CrO}_{4}{ }^{2-}$ ion capture study from water with compound-1 and monitored it with UV-Visible spectroscopy. In situ titration was carried out with $0.25 \mathrm{mM}$ $\mathrm{CrO}_{4}{ }^{2-}$ ions $(2 \mathrm{~mL})$ in water with $1 \mathrm{mg}$ of compound-1 by monitoring the absorption peak at $372 \mathrm{~nm}\left(\lambda_{\max }\right.$ for $\left.\mathrm{CrO}_{4}{ }^{2-}\right)$ in the UV-Vis spectrum (Fig. 2a). The UV-Vis spectra of the supernatant at different time intervals revealed a continuous decrease of the peak at $372 \mathrm{~nm}$ due to the removal of $\mathrm{CrO}_{4}{ }^{2-}$ ions. Almost 77\% removal of the $\mathrm{CrO}_{4}{ }^{2-}$ ions was observed by compound-1 in only $5 \mathrm{~min}$, and reached $\sim 98.25 \%$ with saturation in $30 \mathrm{~min}$ with the decolorization of the solution (Fig. S14 and $\mathrm{S} 15 \dagger)$. The \% removal $v s$. time plot showed the rapid capture of $\mathrm{CrO}_{4}{ }^{2-}$ ions with compound-1 (Fig. 2d). Furthermore, the capacity of compound-1 for $\mathrm{CrO}_{4}{ }^{2-}$ ions was calculated $\left(133 \mathrm{mg} \mathrm{g}^{-1}\right.$ ) from the UV-Vis study and further verified with ICP-AES analysis (Fig. S16 $\dagger$ ). Notably, the capacity of compound-1 for $\mathrm{CrO}_{4}{ }^{2-}$ can be counted as one of the highest values in the area of porous materials (Table S1 $\dagger$ ). The peak at $894 \mathrm{~cm}^{-1}$ in the FT-IR spectra revealed the presence of $\mathrm{CrO}_{4}{ }^{2-}$ in compound-1 $\supset \mathrm{CrO}_{4}{ }^{2-}$ (Fig. S17†). Also, the appearance of $\mathrm{Cr}$ in the EDX analysis affirmed the capture of $\mathrm{CrO}_{4}{ }^{2-}$ in compound-1, whereas the FE-SEM study showed no change in the morphology (Fig. S18-S20 $\dagger$ ).

Apart from $\mathrm{CrO}_{4}{ }^{2-}, \mathrm{TcO}_{4}{ }^{-}$ions also count as hazardous water pollutants due to the radioactive nature of ${ }^{99} \mathrm{Tc}$. As handling such radioactive species is not convenient in a common laboratory, we took $\mathrm{MnO}_{4}{ }^{-}$and $\mathrm{ReO}_{4}{ }^{-}$as model ions which are non-radioactive surrogates for $\mathrm{TcO}_{4}{ }^{-}$. Furthermore, $\mathrm{MnO}_{4}{ }^{-}$and $\mathrm{ReO}_{4}{ }^{-}$ions are close chemical analogues of $\mathrm{TcO}_{4}{ }^{-}$ ions ( $\mathrm{Mn}$, Tc and Re belong to the same group in the periodic table) and also the size of $\mathrm{TcO}_{4}{ }^{-}$ions is in between those of the $\mathrm{MnO}_{4}{ }^{-}$and $\mathrm{ReO}_{4}{ }^{-}$ions, which will help to mimic a real time scenario. Detailed studies of the removal of $\mathrm{MnO}_{4}{ }^{-}$and $\mathrm{ReO}_{4}{ }^{-}$ ions from water were performed similarly to the $\mathrm{CrO}_{4}{ }^{2-}$ ion capture. Here, $2 \mathrm{~mL}$ of the $0.5 \mathrm{mM}$ solutions of each of the oxoanions were used to perform the study with $1 \mathrm{mg}$ of compound1. For the $\mathrm{MnO}_{4}{ }^{-}$ions, the capture study was monitored at $525 \mathrm{~nm}\left(\lambda_{\max }\right)$ while for the $\mathrm{ReO}_{4}{ }^{-}$ions it was monitored at $208 \mathrm{~nm}\left(\lambda_{\max }\right)$ (Fig. 2b and c). For the $\mathrm{MnO}_{4}{ }^{-}$ions, a rapid decrease in the absorption spectra was observed and within 5 minutes the solution was decolorized from purple (Fig. S21 $\dagger$ ). As the size of $\mathrm{ReO}_{4}{ }^{-}$ions is much bigger, relatively slow kinetics were observed as compared to both the $\mathrm{MnO}_{4}{ }^{-}$and the $\mathrm{CrO}_{4}{ }^{2-}$ ions. The presence of $\mathrm{MnO}_{4}{ }^{-}$and $\mathrm{ReO}_{4}{ }^{-}$ions in compound$1 \supset \mathrm{MnO}_{4}{ }^{-}$and compound-1 $\supset \mathrm{ReO}_{4}{ }^{-}$was affirmed by FT-IR and EDX analyses. The peaks at $\sim 902 \mathrm{~cm}^{-1}$ and $\sim 918 \mathrm{~cm}^{-1}$ were observed in the FT-IR spectra for $\mathrm{MnO}_{4}{ }^{-}$and $\mathrm{ReO}_{4}{ }^{-}$ions respectively (Fig. S22 and S23 $\dagger$ ). The EDX analysis revealed the presence of $\mathrm{Mn}$ and Re corresponding to their oxo-anions; whereas the absence of $\mathrm{Cl}^{-}$also confirmed the anion exchange phenomenon (Fig. S24-S27†). FESEM revealed the morphologies of compound-1 $\supset \mathrm{MnO}_{4}{ }^{-}$and compound1 $\supset \mathrm{ReO}_{4}{ }^{-}$remained similar to that of compound-1 (Fig. S28 and $\mathrm{S} 29 \dagger)$. Furthermore, a time dependent decrease in the concentration as well as the \% removal of oxo-anions from water were calculated from UV-Vis profiles (Fig. 2e, f, S30 and S31 $\dagger$ ). Almost 99.9\% of $\mathrm{MnO}_{4}{ }^{-}$ions were removed within $5 \mathrm{~min}$, while for bulky $\mathrm{ReO}_{4}{ }^{-}$ions $>80 \%$ removal was achieved with $1 \mathrm{mg}$ of compound-1 within only 60 minutes (Fig. 2e and f). Enthused by this, we checked the capacity of compound-1 for each of the oxoanions from UV-Vis studies (Fig. S32 and S33†) and further verified this from the ICP-AES analyses. Notably, the high capacities of each of the oxo-anions $\left(\mathrm{MnO}_{4}{ }^{-}: 297.3 \mathrm{mg} \mathrm{g}^{-1}\right.$ $\mathrm{ReO}_{4}{ }^{-}: 517 \mathrm{mg} \mathrm{g}^{-1}$ ) were again some of the highest values in the area of porous materials (Table $\mathrm{S} 2 \dagger$ ). Furthermore, it was found that removal of both the $\mathrm{CrO}_{4}{ }^{2-}$ and $\mathrm{ReO}_{4}{ }^{-}$ions with compound-1 follows the pseudo second order kinetics (Fig. S37 and $\mathrm{S} 38^{\dagger}$ ).

By virtue of such a high capacity, we thought to explore the oxo-anion capture by mimicking real time situations. Waste water contains other competing anions $\left(\mathrm{Cl}^{-}, \mathrm{NO}_{3}{ }^{-}, \mathrm{SO}_{4}{ }^{2-}\right.$ etc. $)$ along with the targeted oxo-anions. In this regard, we performed binary mixture studies for all of the oxo-anions with different competing anions $\left(\mathrm{Cl}^{-}, \mathrm{Br}^{-}, \mathrm{NO}_{3}{ }^{-}\right.$and $\left.\mathrm{SO}_{4}{ }^{2-}\right)$. A considerable amount of capture of the respective oxo-anions was observed even in the presence of competing anions (Fig. $2 \mathrm{~g}-\mathrm{i}$ ). Removal of the $\mathrm{MnO}_{4}{ }^{-}$ions remains undisturbed even in the presence of other anions, while $\geq 80 \% \mathrm{ReO}_{4}{ }^{-}$was captured by compound-1 from the mixture (Fig. $2 \mathrm{~h}$ and i). In the case of the $\mathrm{CrO}_{4}{ }^{2-}$ ion, efficient removal was observed in the presence of $\mathrm{Br}^{-}, \mathrm{NO}_{3}{ }^{-}$and $\mathrm{SO}_{4}{ }^{2-}$ ions (Fig. 2g). Only the mixture of $\mathrm{Cl}^{-}: \mathrm{CrO}_{4}{ }^{2-}$ ions exhibited a relatively lower efficiency $(\sim 70 \%)$ which may be due to the presence of $\mathrm{Cl}^{-}$ions in both compound-1 and in solution. This binary mixture study showed the efficiency of compound-1 in capturing oxo-anions even in the presence of competing anions. In addition, since the $\mathrm{pH}$ of waste water can vary in different ranges, we performed removal of $\mathrm{CrO}_{4}{ }^{2-}$ ions in both acidic and alkaline media (Fig. S39†). While $\mathrm{TcO}_{4}{ }^{-}$ions are mostly found in alkaline media, we demonstrated the removal of $\mathrm{ReO}_{4}{ }^{-}$ions in alkaline media (Fig. S40 $\dagger$ ). Again, the reusability of compound-1 was tested with a $3 \mathrm{M} \mathrm{HCl}$ solution. In the case of both $\mathrm{CrO}_{4}{ }^{2-}$ and $\mathrm{ReO}_{4}{ }^{-}$ions, compound-1 was found to maintain its efficiency without any significant changes for up to four cycles (Fig. S41 and $\mathbf{S 4 2}$ ). This study showed that compound-1 was also stable even after the capture of the respective oxo-anions and regeneration with $3 \mathrm{M} \mathrm{HCl}$, and was further useful for the capture of those anions over a period of cycles.

Moreover, a chromatographic column was prepared embedded with compound-1 and employed for the removal of oxo-anions from water (Fig. S43†). A $2.5 \mathrm{mM}$ stock solution of each of the oxo-anions was passed through the column (see the video in the $\mathrm{ESI} \dagger$ ). For $\mathrm{MnO}_{4}{ }^{-}$and $\mathrm{CrO}_{4}{ }^{2-}$ ions, a distinct color change of the eluent was noticed, as a consequence of being captured by compound-1 (Fig. 3a and c). Furthermore, UV-Vis studies revealed the absence of the oxo-anions in the eluted water, which ascertained that the compound-1 based column 
can be useful for the removal of toxic oxo-anions (Fig. 3b, d and S44 $\dagger$ ). To validate whether the process is anion exchange or surface adsorption in the column, water was passed through the compound-1 $\supset$ oxo-anion loaded column (see the video in the ESI $\dagger$ ). A colorless eluent affirmed the anion exchange process, discarding any option of surface adsorption. In addition, as the compound-1 can be regenerated after treatment with $3 \mathrm{M} \mathrm{HCl}$ solution, we tried to reuse the column in a similar way. When $3 \mathrm{M} \mathrm{HCl}$ was passed through the column, a yellow colored solution came out corresponding to the $\mathrm{Cr}(\mathrm{vI})$ oxo-anions (Fig. $\mathrm{S} 45 \dagger$ ). The column was used further for a second cycle of the $\mathrm{CrO}_{4}{ }^{2-}$ ion capture study (Fig. S46†).

\section{Conclusions}

In conclusion, the rapid capture of oxo-anions from water was demonstrated with an ionic viologen based covalently linked organic network (compound-1) owing to its chemical stability and the presence of free exchangeable $\mathrm{Cl}^{-}$ions inside the network. Rapid decolorization of the yellow colored $\mathrm{CrO}_{4}{ }^{2-}$ solution was observed due to the removal of $\mathrm{CrO}_{4}{ }^{2-}$ ions from water in the presence of compound-1. Furthermore, to study the capture of the radioactive ${ }^{99} \mathrm{Tc}$ based oxo-anion $\left(\mathrm{TcO}_{4}{ }^{-}\right)$, the close analogues $\mathrm{MnO}_{4}{ }^{-}$and $\mathrm{ReO}_{4}{ }^{-}$were used as a surrogate of $\mathrm{TcO}_{4}{ }^{-}$. The capacities for each of the oxo-anions were found to be high and comparable with some of the well studied materials known for their highest capacities. As waste water contains competing anions like $\mathrm{Cl}^{-}, \mathrm{NO}_{3}{ }^{-}, \mathrm{SO}_{4}{ }^{2-}$ etc. along with toxic oxo-anions, we demonstrated efficient capture of the oxo-anions with compound-1 even in the concurrent presence of competing anions. These results demonstrate a unique class of features where the dual capture of toxic oxo-anions has been well performed by a porous organic material which is not common in this area. We believe that this result can open up a new avenue for the capture of toxic anions based on ionic porous covalently linked organic materials.

\section{Conflicts of interest}

There are no conflicts to declare.

\section{Acknowledgements}

P. S. and P. C. acknowledge UGC (India) and INSPIRE (India) for their fellowships respectively. S. D. and A. D. are thankful to IISER Pune for fellowships. S. K. G. acknowledges funding support from the DST-SERB project (EMR/2016/000410), IISER Pune and DST Nanomission Thematic Unit, Govt. of India.

\section{Notes and references}

1 L. H. Keith and W. A. Teillard, Environ. Sci. Technol., 1979, 13, 416-423.

2 Toxicological Profile for Chromium, Public Health Service Agency for Toxic Substances and Diseases Registry, U.S. Department of Health and Human Services, Atlanta, GA, 2012.
3 R. Vonburg and D. Liu, J. Appl. Toxicol., 1993, 13, 225-230.

4 H. Fei, D. L. Rogow and S. R. J. Oliver, J. Am. Chem. Soc., 2010, 132, 7202-7209.

5 R. Cao, B. D. McCarthy and S. J. Lippard, Inorg. Chem., 2011, 50, 9499-9507.

6 L. Khezami and R. Capart, J. Hazard. Mater., 2005, 123, 223231.

7 M. B. Luo, Y. Y. Xiong, H. Q. Wu, X. F. Feng, J. Q. Li and F. Luo, Angew. Chem., Int. Ed., 2017, 56, 16376-16379.

8 W. Liu, Y. Wang, Z. Bai, Y. Li, Y. Wang, L. Chen, L. Xu, J. Diwu, Z. Chai and S. Wang, ACS Appl. Mater. Interfaces, 2017, 9, 16448-16457.

9 S. R. J. Oliver, Chem. Soc. Rev., 2009, 38, 1868-1881.

10 C. Pellerin and S. M. Booker, Environ. Health Perspect., 2000, 108, A402-A407.

11 H. Yoshitake, T. Yokoi and T. Tatsumi, Chem. Mater., 2002, 14, 4603-4610.

12 The World's Worst Pollution Problems 2016: The Toxics Beneath Our Feet, Pure Earth and Green Cross Switzerland, 2016, http://www.worstpolluted.org/docs/ WorldsWorst2016.pdf.

13 S. Wang, P. Yu, B. A. Purse, M. J. Orta, J. Diwu, W. H. Casey, B. L. Phillips, E. V. Alekseev, W. Depmeier, D. T. Hobbs and T. E. Albrecht-Schmitt, Adv. Funct. Mater., 2012, 22, 22412250.

14 T. H. Boyer and P. C. Singer, Environ. Sci. Technol., 2008, 42, 608-613.

15 B. Gammelgaard, Y. P. Liao and O. Jons, Anal. Chim. Acta, 1997, 354, 107-113.

16 B. Wen, X. Q. Shan and J. Lian, Talanta, 2002, 56, 681-687.

17 A. Syty, R. G. Christensen and T. C. Rains, J. Anal. At. Spectrom., 1988, 3, 193-197.

18 D. Sheng, L. Zhu, C. Xu, C. Xiao, Y. Wang, Y. Wang, L. Chen, J. Diwu, J. Chen, Z. Chai, T. E. Albrecht-Schmitt and S. Wang, Environ. Sci. Technol., 2017, 51, 3471-3479.

19 D. Banerjee, D. Kim, M. J. Schweiger, A. A. Kruger and P. K. Thallapally, Chem. Soc. Rev., 2016, 45, 2724-2739.

20 A. V. Desai, B. Manna, A. Karmakar, A. Sahu and S. K. Ghosh, Angew. Chem., Int. Ed., 2016, 55, 7811-7815.

21 L. Zhu, D. Sheng, C. Xu, X. Dai, M. A. Silver, J. Li, P. Li, Y. Wang, Y. Wang, L. Chen, C. Xiao, J. Chen, R. Zhou, C. Zhang, O. K. Farha, Z. Chai, T. E. Albrecht-Schmitt and S. Wang, J. Am. Chem. Soc., 2017, 139, 14873-14876.

22 P.-F. Shi, B. Zhao, G. Xiong, Y.-L. Hou and P. Cheng, Chem. Commun., 2012, 48, 8231-8233.

23 A. J. Howarth, Y. Liu, J. T. Hupp and O. K. Farha, CrystEngComm, 2015, 17, 7245-7253.

24 H. Fei, M. R. Bresler and S. R. J. Oliver, J. Am. Chem. Soc., 2011, 133, 11110-11113.

25 H. Fei, C. S. Han, J. C. Robins and S. R. J. Oliver, Chem. Mater., 2013, 25, 647-652.

26 D. Banerjee, W. Xu, Z. Nie, L. E. V. Johnson, C. Coghlan, M. L. Sushko, D. Kim, M. J. Schweiger, A. A. Kruger, C. J. Doonan and P. K. Thallapally, Inorg. Chem., 2016, 55, 8241-8243.

27 X. Li, H. Xu, F. Kong and R. Wang, Angew. Chem., Int. Ed., 2013, 52, 13769-13773. 
28 H.-R. Fu, Z.-X. Xu and J. Zhang, Chem. Mater., 2015, 27, 205210.

29 Q. Zhang, J. Yu, J. Cai, L. Zhang, Y. Cui, Y. Yang, B. Chen and G. Qian, Chem. Commun., 2015, 51, 14732-14734.

30 H. Fei and S. R. J. Oliver, Angew. Chem., Int. Ed., 2011, 50, 9066-9070.

31 J. J. Neeway, R. M. Asmussen, A. R. Lawter, M. E. Bowden, W. W. Lukens, D. Sarma, B. J. Riley, M. G. Kanatzidis and N. P. Qafoku, Chem. Mater., 2016, 28, 3976-3983.

32 S. Rapti, A. Pournara, D. Sarma, I. T. Papadas, G. S. Armatas, A. C. Tsipis, T. Lazarides, M. G. Kanatzidis and M. J. Manos, Chem. Sci., 2016, 7, 2427-2436.

33 C.-P. Li, B.-L. Liu, L. Wang, Y. Liu, J.-Y. Tian, C.-S. Liu and M. Du, ACS Appl. Mater. Interfaces, 2017, 9, 7202-7208.

34 H. Yang and H. Fei, Chem. Commun., 2017, 53, 7064-7067. 35 S. Rapti, D. Sarma, S. A. Diamantis, E. Skliri, G. S. Armatas, A. C. Tsipis, Y. S. Hassan, M. Alkordi, C. D. Malliakas, M. G. Kanatzidis, T. Lazarides, J. C. Plakatouras and M. J. Manos, J. Mater. Chem. A, 2017, 5, 14707-14719.

36 L. Zhu, L. Zhang, J. Li, D. Zhang, L. Chen, D. Sheng, S. Yang, C. Xiao, J. Wang, Z. Chai, T. E. Albrecht-Schmitt and S. Wang, Environ. Sci. Technol., 2017, 51, 8606-8615.

37 X. Zhao, X. Bu, T. Wu, S.-T. Zheng, L. Wang and P. Feng, Nat. Commun., 2013, DOI: 10.1038/ncomms3344.

38 A. V. Desai, A. Roy, P. Samanta, B. Manna and S. K. Ghosh, iScience, 2018, 3, 21-30.

39 Y. Li, Z. Yang, Y. Wang, Z. Bai, T. Zheng, X. Dai, S. Liu, D. Gui, W. Liu, M. Chen, L. Chen, J. Diwu, L. Zhu, R. Zhou, Z. Chai, T. E. Albrecht-Schmitt and S. Wang, Nat. Commun., 2017, DOI: 10.1038/s41467-017-01208-w.

40 X. Feng, X. Ding and D. Jiang, Chem. Soc. Rev., 2012, 41, 6010-6022.

41 A. G. Slater and A. I. Cooper, Science, 2017, 348, DOI: 10.1126/science.aaa8075.

42 H. M. El-Kaderi, J. R. Hunt, J. L. Mendoza-Cortés, A. P. Côté, R. E. Taylor, M. O'Keeffe and O. M. Yaghi, Science, 2007, 316, 268-272.

43 A. Karmakar, A. V. Desai and S. K. Ghosh, Coord. Chem. Rev., 2016, 307, 313-341.

44 S. Furukawa, J. Reboul, S. Diring, K. Sumida and S. Kitagawa, Chem. Soc. Rev., 2014, 43, 5700-5734.

45 A. J. Howarth, M. J. Katz, T. C. Wang, A. E. Platero-Prats, K. W. Chapman, J. T. Hupp and O. K. Farha, J. Am. Chem. Soc., 2015, 137, 7488-7494.

46 T. Kitao, Y. Zhang, S. Kitagawa, B. Wang and T. Uemura, Chem. Soc. Rev., 2017, 46, 3108-3133.

47 Z. Hu, B. J. Deibert and J. Li, Chem. Soc. Rev., 2014, 43, 58155840.

48 W. Lu, D. Yuan, J. Sculley, D. Zhao, R. Krishna and H. C. Zhou, J. Am. Chem. Soc., 2011, 133, 18126-18129.

49 S. Keskin, T. M. van Heest and D. S. Sholl, ChemSusChem, 2010, 3, 879-891.

50 W. Lu, D. Yuan, D. Zhao, C. I. Schilling, O. Plietzsch, T. Muller, S. Bräse, J. Guenther, J. Blümel, R. Krishna, Z. Li and H.-C. Zhou, Chem. Mater., 2010, 22, 5964-5972.

51 M. G. Rabbani and H. M. El-Kaderi, Chem. Mater., 2011, 23, 1650-1653.
52 S. Das, P. Heasman, T. Ben and S. Qiu, Chem. Rev., 2017, 117, 1515-1563.

53 P. J. Waller, F. Gándara and O. M. Yaghi, Acc. Chem. Res., 2015, 48, 3053-3063.

54 L. Zou, Y. Sun, S. Che, X. Yang, X. Wang, M. Bosch, Q. Wang, H. Li, M. Smith, S. Yuan, Z. Perry and H.-C. Zhou, Adv. Mater., 2017, 29, 1700229.

55 Y. Xu, S. Jin, H. Xu, A. Nagai and D. Jiang, Chem. Soc. Rev., 2013, 42, 8012-8031.

56 U. Diaza and A. Corma, Coord. Chem. Rev., 2016, 311, 85-124. 57 P. Samanta, A. V. Desai, B. Anothumakkool, M. M. Shirolkar, A. Karmakar, S. Kurungot and S. K. Ghosh, J. Mater. Chem. A, 2017, 5, 13659-13664.

58 R. P. Bisbey and W. R. Dichtel, ACS Cent. Sci., 2017, 3, 533543.

59 B. Aguila, Q. Sun, J. A. Perman, L. D. Earl, C. W. Abney, R. Elzein, R. Schlaf and S. Ma, Adv. Mater., 2017, 29, DOI: 10.1002/adma.201700665.

60 P. Samanta, P. Chandra, A. V. Desai and S. K. Ghosh, Mater. Chem. Front., 2017, 1, 1384-1388.

61 Y. Su, Y. Wang, X. Li, X. Li and R. Wang, ACS Appl. Mater. Interfaces, 2016, 8, 18904-18911.

62 D. Banerjee, S. K. Elsaidi, B. Aguila, B. Li, D. Kim, M. J. Schweiger, A. A. Kruger, C. J. Doonan, S. Ma and P. K. Thallapally, Chem.-Eur. J., 2016, 22, 17581-17584.

63 B. Li, Y. Zhang, D. Ma, Z. Xing, T. Ma, Z. Shi, X. Ji and S. Ma, Chem. Sci., 2016, 7, 2138-2144.

64 N. Huang, P. Wang, M. A. Addicoat, T. Heine and D. Jiang, Angew. Chem., Int. Ed., 2017, 56, 4982-4986.

65 H. Ma, B. Liu, B. Li, L. Zhang, Y.-G. Li, H.-Q. Tan, H.-Y. Zang and G. Zhu, J. Am. Chem. Soc., 2016, 138, 5897-5903.

66 S. Fischer, A. Schimanowitz, R. Dawson, I. Senkovska, S. Kaskel and A. Thomas, J. Mater. Chem. A, 2014, 2, 11825-11829.

67 S. Mitra, S. Kandambeth, B. P. Biswal, M. A. Khayum, C. K. Choudhury, M. Mehta, G. Kaur, S. Banerjee, A. Prabhune, S. Verma, S. Roy, U. K. Kharul and R. Banerjee, J. Am. Chem. Soc., 2016, 138, 2823-2828.

68 Z. Li, H. Li, X. Guan, J. Tang, Y. Yusran, Z. Li, M. Xue, Q. Fang, Y. Yan, V. Valtchev and S. Qiu, J. Am. Chem. Soc., 2017, 139, 17771-17774.

69 S.-B. Yu, H. Lyu, J. Tian, H. Wang, D.-W. Zhang, Y. Liu and Z.-T. Li, Polym. Chem., 2016, 7, 3392-3397.

70 O. Buyukcakir, S. H. Je, S. N. Talapaneni, D. Kim and A. Coskun, ACS Appl. Mater. Interfaces, 2017, 9, 7209-7216.

71 C. Hua, B. Chan, A. Rawal, F. Tuna, D. Collison, J. M. Hook and D. M. D’Alessandro, J. Mater. Chem. C, 2016, 4, 2535-2544.

72 O. Buyukcakir, S. H. Je, D. S. Choi, S. N. Talapaneni, Y. Seo, Y. Jung, K. Polychronopoulou and A. Coskun, Chem. Commun., 2016, 52, 934-937.

73 G. Chen, Y. Zhou, X. Wang, J. Li, S. Xue, Y. Liu, Q. Wang and J. Wang, Sci. Rep., 2015, 5, 11236-1-11236-14.

74 G. Das, T. Skorjanc, S. K. Sharma, F. Gándara, M. Lusi, D. S. S. Rao, S. Vimala, S. K. Prasad, J. Raya, D. S. Han, R. Jagannathan, J.-C. Olsen and A. Trabolsi, J. Am. Chem. Soc., 2017, 139, 9558-9565.

75 G. Das, T. Prakasam, S. Nuryyeva, D. S. Han, A. Abdel-Wahab, J.-C. Olsen, K. Polychronopoulou, C. Platas-Iglesias, 
F. Ravaux, M. Jouiad and A. Trabolsi, J. Mater. Chem. A, 2016, 77 R. Gomes, P. Bhanja and A. Bhaumik, Chem. Commun., 2015, 4, 15361-15369. 51, 10050-10053.

76 L.-Z. Peng, P. Liu, Q.-Q. Cheng, W.-J. Hu, Y. A. Liu, J.-S. Li, 78 S. Asaftei, D. Huskens and D. Schols, J. Med. Chem., 2012, 55, B. Jiang, X.-S. Jia, H. Yang and K. Wen, Chem. Commun., 10405-10413. 2018, 54, 4433-4436. 